\title{
Healthcare seeking for diarrhoea, malaria and pneumonia among children in four poor rural districts in Sierra Leone in the context of free health care: results of a cross-sectional survey
}

\author{
Theresa Diaz ${ }^{1 *}$, Asha S George ${ }^{1,2+}$, Sowmya R Rao ${ }^{3,4+}$, Peter S Bangura ${ }^{5 \dagger}$, John B Baimba ${ }^{6 \dagger}$, \\ Shannon A McMahon ${ }^{2+}$ and Augustin Kabano ${ }^{6+}$
}

\begin{abstract}
Background: To plan for a community case management (CCM) program after the implementation of the Free Health Care Initiative (FHCl), we assessed health care seeking for children with diarrhoea, malaria and pneumonia in 4 poor rural districts in Sierra Leone.

Methods: In July 2010 we undertook a cross-sectional household cluster survey and qualitative research. Caregivers of children under five years of age were interviewed about healthcare seeking. We evaluated the association of various factors with not seeking health care by obtaining adjusted odds ratios and $95 \%$ confidence limits using a multivariable logistic regression model. Focus groups and in-depth interviews of young mothers, fathers and older caregivers in 12 villages explored household recognition and response to child morbidity.

Results: The response rate was $93 \%$ ( $n=5951$ ). Over $85 \%$ of children were brought for care for all conditions. However, $10.8 \%$ of those with diarrhoea, $36.5 \%$ of those with presumed pneumonia and $41.0 \%$ of those with fever did not receive recommended treatment. In the multivariable models, use of traditional treatments was significantly associated with not seeking outside care for all three conditions. Qualitative data showed that traditional treatments were used due to preferences for locally available treatments and barriers to facility care that remain even after $\mathrm{FHCl}$.

Conclusion: We found high healthcare seeking rates soon after the $\mathrm{FHCl}$; however, many children do not receive recommended treatment, and some are given traditional treatment instead of seeking outside care. Facility care needs to be improved and the CCM program should target those few children still not accessing care.
\end{abstract}

\section{Background}

Sierra Leone emerged in 2002 from 11 years of civil war, and today has some of the worst health indicators in the world. In 2010, infant mortality was estimated to be 114 per 1000 live births and under five mortality was estimated to be 174 per 1000 live births, ranking Sierra Leone fifth highest in the world for child mortality [1]. In 2008, Sierra Leone only had 1.9 physicians, nurses and midwives per 10,000 populations in contrast to the

\footnotetext{
* Correspondence: tdiaz@unicef.org

${ }^{\dagger}$ Equal contributors

'Knowledge Management and Implementation Research Unit, Health Section, Programme Division, United Nations Children's Fund (UNICEF) New York NY, USA

Full list of author information is available at the end of the article
}

estimated 23 per 10,000 population estimated to be needed to deliver basic maternal and child health care services [2]. Government primary health care services consists of peripheral health units, with the latter staffed by nurses, paid community health officers and maternal and child health officers. Villages are also served by travelling drug peddlers and a range of herbalists.

In 2005, due to the high child mortality and the severe lack of health manpower, the Ministry of Health and Sanitation (MOHS) of Sierra Leone allowed non-governmental organizations to deliver community case management (CCM) with community health volunteers (CHVs) in rural areas to increase coverage of treatment for malaria (artemisinin-based combination therapies [ACT]), 
pneumonia (co-trimoxazole), and diarrhoea (oral rehydration solution [ORS]) for sick children. This form of CCM was first piloted in Kono district in 2006. To further pilot this approach it was decided to extend this type of CCM with the addition of zinc for diarrhoea to two additional poor and marginalized districts. Selection of additional districts was based on a composite score that included wealth status, immunization and stunting rates and availability of health services. Of the 7 districts with the worst composite score, 6 did not have CCM. Of these 6, 2 were chosen in two different parts of the country (Kambia, Pujehun) to receive CCM and 2 remaining districts nearby that would not receive CCM were chosen as a comparison (Kailahun and Tonkolili). In addition to piloting CCM, in April 2010, the government of Sierra Leone launched the Free Health Care Initiative (FHCI) for pregnant and breast-feeding women and children under five years of age. The removal of user fees for this target group was also supported by a strengthening of the drug supply chain and increased pay for health workers. In the month before FHCI began, about 170,000 children received care from Sierra Leone's hospital facilities, while in the month after FHCI, the number exceeded 340,000 [3].

Although it has been shown that CCM is very effective and $\mathrm{CHWs}$ can supplement facility services in rural underserved areas, [4-7] it is not known how such a program should be implemented in the context of removal of user fees in public health facilities. We describe the results of baseline quantitative and qualitative assessments conducted after the implementation of the FHIC and prior to implementation of CCM, relating to child health care seeking for diarrhoea, pneumonia and fever in children less than five years of age in four districts in Sierra Leone. Our research was conducted for the purpose of understanding health use patterns and as the baseline data collection for evaluation for CCM. We examined the initial responses of caregivers to the FHCI, gathered some information on the type of care being delivered through this initiative to better inform the implementation of the CCM program.

\section{Methods}

\section{Sampling for quantitative household survey}

Between June and July 2010 a household cluster survey was conducted in four districts (two districts that would receive $C C M$ in the future and two comparison districts that would not receive $\mathrm{CCM}$ ) to obtain baseline data before the implementation of CCM. A sample of 1500 households in each of the four districts was selected for the survey (3000 for the districts that would receive CCM and 3000 for the districts that would not receive CCM). Within each district, 50 clusters were selected based on population proportional to size sampling. Using personal digital assistants (PDA) with global positioning system (GPS) devices, household enumeration was conducted in each cluster and 30 households were randomly sampled. Details of this method have been described elsewhere [8].

\section{Quantitative household survey questionnaires}

Three questionnaires were used based on previous Demographic and Health Survey (DHS) and Multiple Indicator Cluster Survey (MICS) questionnaires for each household. The head of the household or a responsible adult was interviewed to determine household characteristics, and caregivers of all children under five years of age were asked about child morbidity and care seeking for diarrhoea, respiratory and fever symptoms two weeks prior to the survey. The questionnaire was programmed using Visual CE (Cambridge, MA) professional edition version 12 with multiple data checks and uploaded onto PDAs.

Heads of households in Sierra Leone were asked permission to interview others in the household including girls 15 to 17 years of age, prior to seeking consent from all women/caretakers over 18 years of age and girls under 18 who are married or have children. Laminated consent forms were provided to all interviewers. Given the high illiteracy rate verbal consent was obtained. The interviewer was required to check off on the PDA whether the consent was read and whether permission was given to be allowed to proceed with the interview.

For those children who were ill in the recall period, caregivers were asked whether or not they had sought treatment for the illness from any source. If they had, they were asked where they sought treatment first (e.g. public hospital, community health center, mobile clinic, pharmacy, private hospital or physician, another house); from whom (e.g. physician, nurse, health aide, pharmacist, paid community health officer, peddler, $\mathrm{CHV}$, herbalist); and with visual aids, what type of treatment they received (e.g. ORS, zinc, co-trimoxazole, ACT, other anti-malarials, another antibiotic, another pill that is commonly used to control fever or diarrhoea but was not an antibiotic). Caregivers were also asked if they had used any other remedy including homemade sugar salt solution (SSS), traditional remedies such as drinking hot fluids with herbs, hot sponging with goat fat soap, goat oil ointment, and boiled herbs.

\section{Analysis of quantitative household survey}

Our analysis is only based on children under 5 whose caretakers were interviewed. We computed weights that accounted for the complex survey design and nonresponse and used them in all our analyses that were conducted in SAS version 9.1 [9]. We calculated wealth quintiles within our sample based on household assets 
using principle components analysis [10]. Two week prevalence of diarrhoea and fever was calculated as the proportion of all children with such symptoms. In addition 'possible pneumonia' was defined as cough with or without fever and difficulty breathing that was due to a problem in the chest; the standard definition used in DHS and MICS surveys. Recommended treatment was defined as follows: for diarrhoea, zinc and ORS (but not homemade SSS); for pneumonia, any antibiotic; and for fever, ACTs. To calculate distance from the household to the nearest clinic we compared our GPS data to a national GPS survey of health facilities conducted in 2010. We calculated straight line distances to the nearest health facility.

We present weighted percentages and 95\% confidence limits for description of our sample. To test for associations of the factors with not seeking health care in the bivariate analysis we used 2-sided chi-square tests; p values $<0.05$ were considered significant. Odds ratios (OR) and 95\% confidence intervals $(95 \% \mathrm{CI})$ were obtained from a multivariable logistic regression model to assess the factors associated with not seeking health care that controlled for all variables associated with not seeking care in the bivariate analysis or were reported in the literature (age of child, educational level of mother, distance from health facility) as being associated and had conceptual reasons for inclusion.

\section{Qualitative survey}

The qualitative study aimed to provide formative information for the baseline survey and to obtain in-depth information on household recognition and response to child morbidity, particularly along the following themes: illness concepts, terms, causation, prevention, treatment, decision making, barriers to care, patterns of resort, provider preferences, and care burdens. The study design was informed by applied qualitative research, $[11,12]$ an approach that focuses on specific illnesses (diarrhoea, pneumonia, malaria), addresses programmatic concerns related to these illnesses (identifying local causes, terminology and treatment for diarrhoea), and draws from experiences of actual cases of sick children. Focus group discussions captured social norms as expressed by specific sub-groups of concern, while in-depth interviews collected narratives of actual cases of care seeking for child illness.

Data collection took place in two stages, first in April 2010 and later in July 2010, by data collectors who received 5 days of training on qualitative methods and research ethics and were accompanied in the field by a qualitative research supervisor. Data collection focused on three types of villages: those with a community health post, those with a community health center, and those without any government facility in the village and typically located 3-10 miles away or five hours distance from a village with a government health facility.

Focus group discussions and in-depth interviews were conducted with mothers, fathers and older caregivers of children under age five. Participants were selected purposively with the intent to maximize information on child illness and care seeking by drawing on mothers, fathers and caregivers of children under five years of age with the aid of key informants including village elders and health volunteers with efforts made to include a diversity of respondents among in-depth interviews including those living near to and far from the village center. Informed, verbal consent was sought and received from all respondents who partook in 36 focus group discussions and 64 in-depth interviews, including 15 follow-up interviews, which were completed and taped across 12 villages in all 4 districts. Debriefing sessions based on field notes were held during and immediately after fieldwork to further explore deviant or unique findings that merited follow up interviews and to support reflective practice and possible differences in interviewing, probing and interpretation among data collectors. One respondent declined consent due to time constraints. Data collection ceased upon saturation of key themes listed earlier.

Data were transcribed into English and a list of hierarchical codes developed and validated by a co-investigator before being applied to the dataset using Atlas version 4.1 [13]. Thematic analysis was undertaken that compared and contrasted data from different respondents, data collection methods and sites to arrive at triangulated descriptions of illness terminologies, causation, prevention, and treatment patterns. Data summaries were shared with key stakeholders before developing manuscripts. The findings presented here are those that help to further elucidate quantitative findings.

The study received institutional review board approval from the Government of Sierra Leone Office of Science and Ethics Review Committee, Ministry of Health.

\section{Results}

Of 6000 households approached for interview 5527 (92.1\%) agreed to participate. Of these households $67 \%$ had children under 5 for a total of 6429 children of which 5966 (92.8\%) completed questionnaires. Of these 15 were removed due to missing data or incorrect birthdates resulting in 5951 children. Response rates did not differ between districts that would implement CCM and those that would not. Non-response was due mostly to lack of availability of the appropriate respondent. Overall $31.3 \%$ of households with children were polygamous, the vast majority were Muslim (85.6\%) and most were from Mende (36\%) or Temne (45.3\%) tribes (Table 1). 
Table 1 Characteristics of households and children, baseline community case management survey (CCM) in 4 districts in Sierra Leone 2010

\begin{tabular}{|c|c|c|c|c|c|c|}
\hline \multirow[b]{3}{*}{ Variable } & \multirow{2}{*}{\multicolumn{2}{|c|}{$\begin{array}{l}\text { Districts that will } \\
\text { receive CCM } \\
\mathrm{N}=3152\end{array}$}} & \multirow{2}{*}{\multicolumn{2}{|c|}{$\begin{array}{l}\text { Districts that will not } \\
\text { receive CCM } \\
\mathrm{N}=\mathbf{2 7 9 9}\end{array}$}} & \multirow{2}{*}{\multicolumn{2}{|c|}{$\begin{array}{c}\text { Total } \\
\mathrm{N}=5951\end{array}$}} \\
\hline & & & & & & \\
\hline & Weighted\% & 95\% C.L. & Weighted\% & $95 \%$ C.L. & Weighted\% & $95 \%$ C.L. \\
\hline Polygamous household & 38.5 & $33.8-66.2$ & 25.4 & $18.2-32.7$ & 31.3 & $26.9-35.7$ \\
\hline \multicolumn{7}{|l|}{ Religion of head of household } \\
\hline Islam & 94.9 & $92.9-96.9$ & 77.9 & $72.0-83.8$ & 85.6 & $82.1-89.0$ \\
\hline Christian & 4.9 & $2.9-6.9$ & 21.9 & $16.1-27.8$ & 14.2 & $10.8-17.7$ \\
\hline Other & 0.2 & $00-0.6$ & 0.2 & $0-0.3$ & 0.2 & $0.0-0.4$ \\
\hline \multicolumn{7}{|l|}{ Tribe of household: } \\
\hline Mende & 43,4 & $31.7-55.0$ & 29.9 & $19.1-40.8$ & 36.0 & 27.9-44.1 \\
\hline Temne & 33.7 & $23.9-43.5$ & 54.8 & $42.8-66.9$ & 45.3 & 36.9-53.7 \\
\hline Susa & 12.1 & $6.1-18.1$ & 0.1 & $0.0-.0 .2$ & 5.5 & $2.6-8.4$ \\
\hline Limba & 8.1 & $3.5-12.7$ & 4.4 & $0.7-8.1$ & 6.0 & $3.1-8.9$ \\
\hline Kissi & 0.0 & $3.5-12.7$ & 5.6 & $2.4-8.7$ & 3.1 & $1.4-4.8$ \\
\hline Koranko & 0.0 & $0.0-0.0$ & 3.9 & $0.0-7.9$ & 2.1 & $0.0-4.3$ \\
\hline Other & 3.6 & $0.0-0.10 .9-4.5$ & 1.3 & $0.5-2.1$ & 2.0 & $0.3-2.9$ \\
\hline \multicolumn{7}{|l|}{ Selected assets of household: } \\
\hline Radio & 43.6 & $38.1-49.2$ & 35.2 & $30.9-39.4$ & 38.9 & $35.5-42.5$ \\
\hline Mobile phone & 30.6 & $26.7-34.4$ & 23.3 & $18.9-27.7$ & 26.6 & 23.6-29.6 \\
\hline No sanitation & 33.3 & $26.7-38.8$ & 38.7 & $31.9-45.4$ & 36.3 & $31.5-41.1$ \\
\hline Unprotected water & 53.4 & $44.6-62.2$ & 61.5 & $41.6-61.6$ & 57.9 & $51.4-64.4$ \\
\hline Dirt floor & 78.2 & $74.0-82.3$ & 80.6 & 76.9-84.4 & 79.5 & $76.8-82.3$ \\
\hline Electricity & 1.7 & $0.7-2.8$ & 0.3 & $0.1-0.5$ & 0.9 & $0.4-1.5$ \\
\hline Wood cooking & 98.7 & $97.6-99.7$ & 98.9 & $97.8-100$ & 98.8 & $98.0-99.6$ \\
\hline Atleast one women in household went to school & 26.7 & $39.1-49.8$ & 25.8 & 21.8-29.8 & 26.5 & $39.1-49.8$ \\
\hline Proportion of Households in poorest Wealth Quintile: & 18.7 & $14.1-23.3$ & 24.8 & $20.1-29.4$ & 22.0 & $18.7-25.4$ \\
\hline \multicolumn{7}{|l|}{ Household distance to nearest health facility: } \\
\hline$<5 \mathrm{Km}$ & 77.5 & $67.1-87.9$ & 59.2 & $46.5-71.9$ & 67.4 & $58.6-76.3$ \\
\hline$>5 \mathrm{Km}$ & 20.6 & $11.1-30.0$ & 25.0 & 12.4-37.6 & 23.0 & $14.8-31.2$ \\
\hline unknown & 2.0 & $0.4-3.5$ & 15.8 & $6.4-25.1$ & 9.6 & $4.2-14.9$ \\
\hline Male gender of child & 50.0 & $47.5-52.4$ & 48.9 & $46.8-51.0$ & 49.4 & $47.8-51.0$ \\
\hline If child is infant & 24.8 & $22.1-27.6$ & 24.7 & $23.0-26.6$ & 24.8 & $23.2-26.4$ \\
\hline \multicolumn{7}{|l|}{2 week prevalence:: } \\
\hline Diarrhoea & 26.5 & $23.2-29.7$ & 24.9 & $21.4-28.5$ & 25.6 & $23.2-28.0$ \\
\hline Fever & 67.1 & $62.8-71.4$ & 65.5 & $62.1-68.9$ & 66.3 & $63.6-69.0$ \\
\hline Possible pneumonia & 16.9 & $12.2-21.6$ & 22.0 & $19.4-24.7$ & 19.7 & $17.2-22.2$ \\
\hline
\end{tabular}

Over half of the children (66.2\%) had fever, 25.6\% had diarrhoea and $16.9 \%$ had pneumonia in the two weeks prior to the interview. These proportions were similar between CCM districts and comparison districts (Table 1). Multiple conditions were common. Overall, $94 \%$ of children with presumed pneumonia and $84 \%$ of children with diarrhoea had fever, and $23 \%$ of children with diarrhoea had presumed pneumonia. Healthcare seeking behaviours were very high; over $85 \%$ of children were brought for care for all conditions. Healthcare seeking was highest for pneumonia with $90 \%$ of caretakers seeking outside care. Overall, among those that sought treatment, the proportion that did not receive recommended treatment was highest for fever (41\%) followed by presumed pneumonia (36.5\%) and lowest for diarrhoea (10.8\%) (Figure 1). 


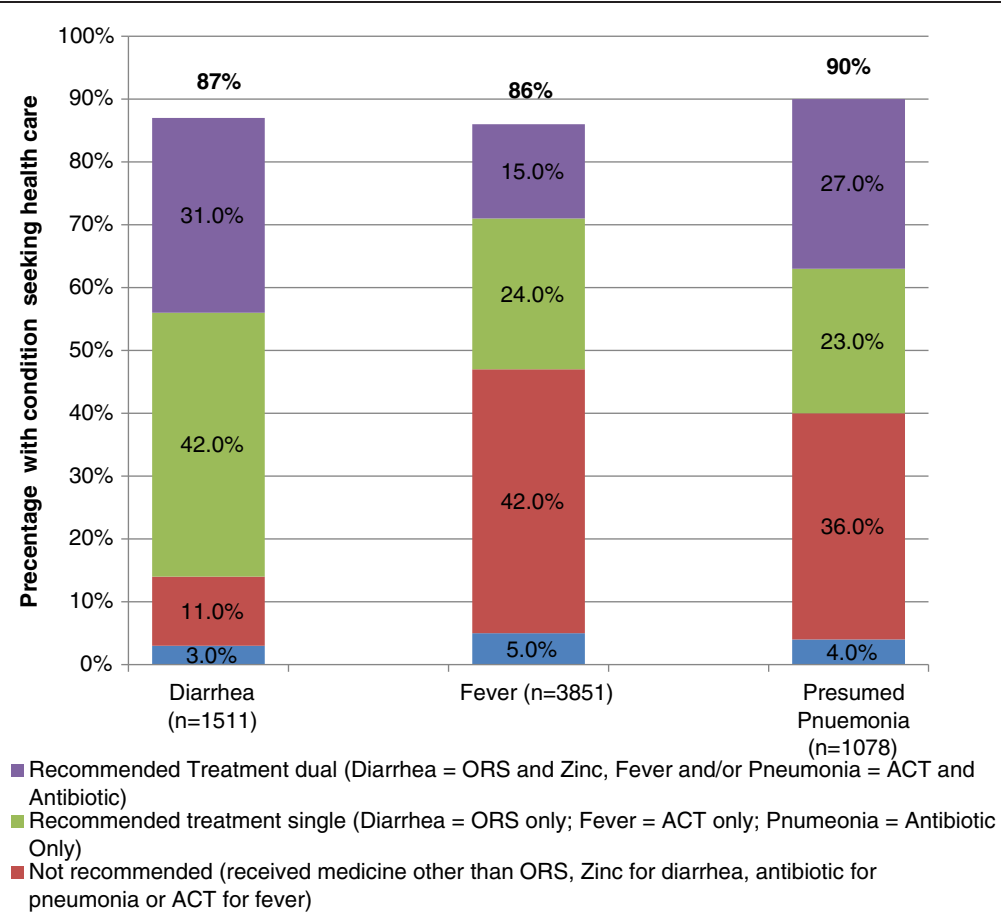

Figure 1 Health seeking behaviors and type of treatment by condition, baseline community case management survey in 4 districts, Sierra Leone 2010**.

Among those that sought care outside the home, over $75 \%$ of children were brought to a public facility, regardless of their illness type. The most common provider of treatment $(60 \%$ or higher) were facility based health professionals (e.g., doctors, nurses, health aides and community health officers), regardless of whether the treatment was recommended or not (Figure 2). Among providers other than facility based health professionals, there were notable differences between those giving recommended vs. not recommended treatments. The proportion of children with diarrhoea that received ORS and Zinc from providers other than facility based health professionals was $12 \%$ for recommended treatments but $30 \%$ for not recommended treatments. The proportion of children with fever received ACT from a peddler was $7 \%$ but $21 \%$ among those that did not receive ACT. The proportion of children that received an antibiotic for presumed pneumonia from others was $1 \%$ but $6 \%$ among those that did not receive an antibiotic (Figure 2).

In the multivariable model group was not significantly associated with not seeking care for diarrhoea and fever but for presumed pneumonia the group receiving CCM was more likely to not seek care (AOR 1.8, 95\% CI 1.0 3.3) (Table 2). For children with diarrhoea those who were given homemade SSS were more likely to not seek healthcare (AOR 2.0, 95\% CI: 1.1-2.4). Also among children with diarrhoea those who had one of the other two conditions were less likely to not seek healthcare $\mathrm{AOR}=0.8$; 95\% CI: 0.6-1.1); children who had all three conditions were the least likely to not seek treatment for diarrhoea (AOR=0.6; 95\% CI: 0.3-1.2). Use of traditional treatments was the one variable significantly associated with not seeking care for all three conditions with AORs ranging from 1.5 to 3.5 (Table 2). Social determinants (polygamy, religion, wealth quintile, mother's education, and distance from health facility) were not associated with health care seeking outside the home for children with diarrhoea and fever. However, for pneumonia children who were from the lowest quintile were less likely to not seek care than others (AOR 0.5, 95\% C.I. 0.3-0.8),

Qualitative data also documented references to high levels of health care seeking from a range of providers (village elders, herbalists, peddlers and government providers) for all three diseases, and at times a high level of confidence in care provided by personnel working in government facilities. For instance a mother in a remote village on discussing treatment for her child with presumed pneumonia reported the following:

R: As I arrived I reported myself to Nurse that my child is not well and she really noticed that the 


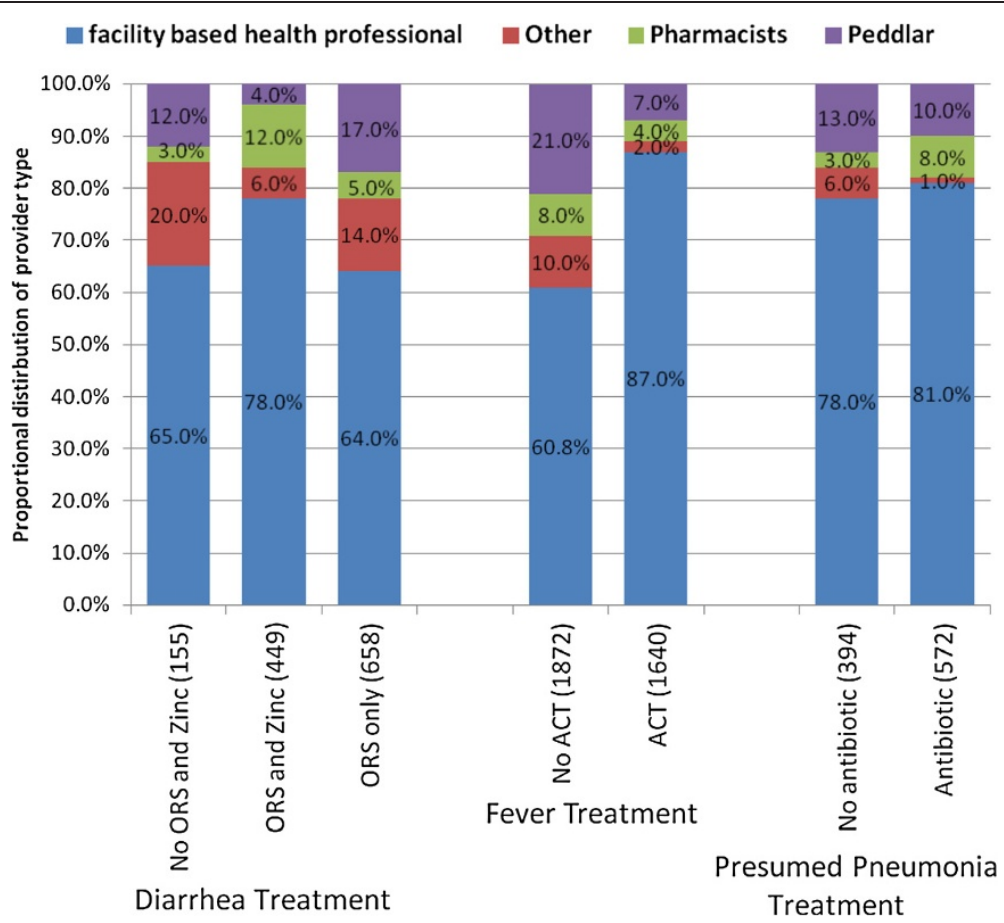

Figure 2 Proportional distribution by provider type of receipt of recommended treatment* or not, community case management baseline survey in 4 districts, Sierra Leone 2010.

sickness was a serious one. She leaves all the work that she was doing to attend to us.

\section{I: What did she do?}

R: She gave the injection and also with some medicine, some to be given in the afternoon and others at night. And she also encouraged me that the child will get well with these medicine.

\section{I: How did you see Nurse?}

R: She is kind hearted. Nurse is always ready to help us day and night.

The qualitative data also highlighted reasons why respondents sought care from different kinds of providers depending on who they saw as working. Perceptions of receiving ineffective treatment due to symptoms not abating often led to respondents switching type of provider, as reported by young mothers from a remote village discussing care-seeking for malaria.

When that gbelui (malaria) starts you take her to the halay weibu (hospital) and you talk to older mothers that gbelui has catch your child and that you are taken her to the halay weibu and she is still sick so what next to (do?)? They will advise that I put herbs together to wash the child but this would depend if it will works for my child. So that is what I would stop: sometimes with the herbs, sometimes with the herbs and halay weibu.

While in some instances, respondents reported that the presence of government providers replaced peddlers, in other instances due to government providers not having medicines or facilities not existing, respondents turned to peddlers for treatment. For example, mothers in a remote village discussed resorting to traditional treatment for pneumonia due to lack of availability of government health facilities and lack of trust in drug peddlers:

M: why is it that it is only traditional medicine you are using to cure this sickness?

R6: since the hospital here was burned down unless we get traditional medicines and also those drug peddlers but even with them their drugs are not good.

Despite the lack of trust in drug peddlers expressed by some respondents, for those living in remote villages purchasing small quantities of drugs from a peddler was reported as more affordable and accessible, even if it did not mean a complete or appropriate regime 
Table 2 Factors associated with not seeking treatment outside the home, by disease, baseline community case management (CCM) survey in 4 districts in Sierra Leone 2010*

\begin{tabular}{|c|c|c|c|c|c|c|c|c|}
\hline \multirow[b]{2}{*}{ Variable } & \multirow[b]{2}{*}{$N$} & \multicolumn{4}{|c|}{ Bivariate } & \multicolumn{3}{|c|}{$\begin{array}{l}\text { Multivariable logistic } \\
\text { regression model }\end{array}$} \\
\hline & & $\begin{array}{l}\% \text { not seeking } \\
\text { healthcare }\end{array}$ & Odds & $\begin{array}{c}95 \% \\
\text { confidence } \\
\text { interval }\end{array}$ & $P$ value & $\begin{array}{l}\text { Adjusted } \\
\text { odds ratio }\end{array}$ & $\begin{array}{c}95 \% \\
\text { confidence } \\
\text { interval }\end{array}$ & $P$ value \\
\hline
\end{tabular}

Diarrhea

1511

District type:

Will not receive

CCM Will receive

CCM $\quad 792 \quad 165 \%$

Age:

$\geq 1$ year

(192.

$1.2,2.5$

.0009

1.5

$0.9,2.4$

0.09

$<1$ year

$1167 \quad 13.7 \%$

$<1$ year

$344 \quad 11.6 \%$

0.8

$0.7,2.1$

0.5

0.7

$0.4,1.2$

Gender:

Male

$772 \quad 12.6 \%$

Female

739

$13.9 \%$

1.1

$0.7,1.7$

0.6

1.0

$0.6,1.5$

Tribe of household:

Other

Temne

$315 \quad 16.1 \%$

Mende

$505 \quad 10.2 \%$

691

$14.3 \%$

$$
0.6
$$

$0.3,1.1$

0.9

$0.5,1.4$

0.2

0.6

$0.3,1.5$

Religion:

Other

$$
240
$$

$8.5 \%$

Muslim

1089

$14.1 \%$

1.7

$0.9,3.3$

0.08

1.6

$0.7,3.8$

0.2

\section{Polygamy}

No

$\begin{array}{ll}1075 & 12.4 \% \\ 436 & 15.2 \%\end{array}$

Yes

436

$15.2 \%$

1.3

$0.8,1.9$

0.2

1.3

$0.9,1.9$

0.2

Household distance to nearest health facility:

$<5 \mathrm{Km}$

$\geq 5 \mathrm{Km}$

unknown

Wealth quintile:

Other

lowest

Atleast one women in household went to school

\section{No}

yes

Traditional treatment

No

Yes

Homemade SSS:

No
Yes

$\begin{array}{ll}1071 & 12.4 \% \\ 302 & 13.9 \% \\ 138 & 10.4 \%\end{array}$

$\begin{array}{ll}1132 & 13.5 \% \\ 379 & 12.3 \%\end{array}$

$\begin{array}{ll}1012 & 11.1 \% \\ 347 & 13.5 \%\end{array}$

1003

508

527

984

$11.1 \%$

$3.5 \%$

$11.2 \%$

$17.5 \%$

$527 \quad 9.1 \%$

$15.2 \%$
$2.4 \%$

$13.9 \%$

$0.4 \%$

1.2

$0.4,1.5$

0.8

$0.3,1.7$

0.6

0.6

1.0

1.0

$0.3,3.0$

$0.4,2.7$

1.0

0.9

$0.6,1.4$

0.6

0.9

$0.5,1.6$

0.8

1.2

$0.8,2.0$

0.4

1.1

$0.7,1.9$

0.6

1.7

$1.2,2.5$

.003

1.5

$1.0,2.2$

0.04

2.0

$1.2,2.5$

.003

2.0

$1.1,2.4$

0.002 
Table 2 Factors associated with not seeking treatment outside the home, by disease, baseline community case management (CCM) survey in 4 districts in Sierra Leone 2010* (Continued)

Disease:

Diarrhea only

$246 \quad 20.8 \%$

Also Fever or presumed pneumonia

$909 \quad 12.9 \%$

Also fever and presumed pneumonia

356

$8.8 \%$

0.6

$0.4,1.1$

Fever

3851

District type:

Will not receive CCM Will receive

$1845 \quad 13.0 \%$

CCM

2006

$$
16.1 \%
$$

1.3

$1.0,1.7$

.07

1.2

$0.9,1.8$

0.1

Age:

$\geq 1$ year

$2922 \quad 15.0 \%$

$<1$ year

929

$13.1 \%$

1.2

$0.9,1.6$

0.3

0.9

$0.6,1.3$

0.6

Gender:

Male

1904

$14.5 \%$

Female

1947

$14.5 \%$

1.0

$0.8,1.2$

0.9

1.0

$0.8,1.2$

0.9

Tribe of household:

Other

$712 \quad 15.1 \%$

Temne

1287

$14.9 \%$

Mende

1852

$14.0 \%$

Religion:

Other

Muslim

Polygamy:

No

Yes

1190

$14.1 \%$

0.9

$0.7,1.2$

0.6

0.9

$0.6,1.4$

Household distance to nearest health facility:

$<5 \mathrm{Km}$

2577

$15.2 \%$

$\geq 5 \mathrm{Km}$

968

$12.1 \%$

$0.4,1.4$

$15.7 \%$

1.0

$0.5,1.9$

0.4

0.6

$0.3,1.2$

Wealth quintile:

306

$15.6 \%$

Other

2957

lowest

894

$15.2 \%$

1.0

$0.5,1.9$

0.2

0.7

$0.5,1.0$

0.08

Atleast one women in household went to school

No

yes

2611

865

Traditional treatment

No

Yes

$\begin{array}{ll}2963 & 11.6 \% \\ 888 & 24.7 \%\end{array}$

Disease:

Fever only

1934

1561

Also diarrhea or presumed pneumonia

Also diarrhea and presumed pneumonia

Presumed Pneumonia
$13.6 \%$

$14.4 \%$

$11.6 \%$

$24.7 \%$

$15.8 \%$

$13.7 \%$

$11.3 \%$ $\begin{array}{llllll}1.1 & 0.8,1.4 & 0.6 & 1.1 & 0.8,1.4 & 0.5\end{array}$

$\begin{array}{llllll}2.5 & 1.8,3.4 & <0.001 & 2.9 & 2.1,4.0 & <.0001\end{array}$

0.7

$0.4,1.2$

0.2

0.8

$0.6,1.1$

0.8

$0.4,1.4$

0.6

$0.3,1.2$

0.2 
Table 2 Factors associated with not seeking treatment outside the home, by disease, baseline community case management (CCM) survey in 4 districts in Sierra Leone 2010* (Continued)

District type:

Will not receive CCM Will receive

607

CCM

408

\section{$8.7 \%$}

Age:

$\geq 1$ year

$<1$ year

\section{8}

240

\section{$9.8 \%$}

Gender:

Male

Female

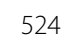

554

$9.6 \%$

Tribe of household:

Other

Temne

Mende

Religion:

Other

Muslim

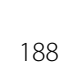

$$
10.8 \%
$$

1.1

$0.7,2.0$

$8.8 \%$

$262 \quad 12.3 \%$

628

$9.9 \%$

1.4

$0.7,3.3$

$0.6,2.5$

$7.3 \%$

$10.7 \%$

1.5

$0.8,3.1$

$9.2 \%$

$12.1 \%$

1.4

$0.8,2.5$

0.3

1.2

$0.7,2.3$

0.4

Household distance to nearest health facility:

$<5 \mathrm{Km}$

798

$\geq 5 \mathrm{Km}$

unknown

209

$11.0 \%$

$6.3 \%$

$13.3 \%$

0.4

$0.1,1.4$

$0.4,3.4$

0.2

0.4

$0.1,1.4$

1.2

$13.9 \%$

Other

795

lowest

283

$9.1 \%$

0.6

$0.3,1.0$

0.05

0.5

$0.3,0.8$

0.008

Atleast one women in household went to school

No

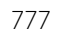

$8.8 \%$

yes

$183 \quad 14.6 \%$

Traditional treatment

No

Yes

$\begin{array}{ll}776 & 7.1 \% \\ 302 & 18.4 \%\end{array}$

1.8

$1.0,2.9$

0.04

1.6

$0.8,3.3$

0.2

Disease:

Presumed Pneumonia only

Also Fever or diarrhea

48

674

$14.1 \%$

Also fever and diarrhea
$9.4 \%$

$11.3 \%$
2.9

$1.7,5.2$

$<.001$

3.5

$2.0,6.2$

$<.001$
0.8

1.2

\section{$0.3,2.2$}

$0.6,2.4$
0.6

$0.2,1.8$

0.6

0.7

$0.2,2.4$ of medication, than traveling across difficult terrain to access government providers.

Reasons for resorting to traditional treatments included both respect for village elders and herbalists as providers and causal beliefs that categorised the illness as not requiring biomedical treatment. At the same time, respondents also recounted resorting to traditional treatment due to lack of access to government services, lack of financial means or lack of trust in peddlers For example, fathers in a village with a government facility discussing treatment for diarrhoea and resort to elders for care due to lack of medicines from health facilities and trust in their care:

$\mathrm{R}$ : well the point is that if we do not have the medicine from the hospital, we do normally carry the child to the old mothers. 
I: so you said, you carry the child to the old mother why?

R: the old mothers who knows the medicine can cure the child.

In terms of reporting barriers to care, despite the advent of FCHI, first and foremost was the expense of seeking care from government services, especially when located in remote villages. Fathers in a village situated with a government facility discussing treatment for malaria mentioning resort to traditional treatment due to costs in accessing care at health facilities:

R: Some times when our children get sick we don't have money to take them to the hospital and we don't want the illness to get worst so we treat them traditionally.

Lack of access to government facilities was also due to lack of facilities from destruction during the war, distance across difficult terrain, or due to the facility being closed when the child falls ill at night.

\section{Discussion}

The results of our survey from four rural districts in Sierra Leone found higher rates of healthcare seeking behaviours for all three conditions $(>85 \%)$ than have been reported in surveys prior to the FHCI. In the rural sample of the 2008 Demographic Health Survey (DHS), [14] $47 \%$ of children with diarrhoea, $45 \%$ of children with presumed pneumonia and $47 \%$ of children with fever were brought for health care. Similarly in the 2009 rural Sierra Leone District Health Services Baseline Survey (SLDHBS), [15] these rates were 40\%, $50 \%$ and $52 \%$ respectively. In spite of this high rate of healthcare seeking behaviour many children did not receive the recommended treatment and there were still some children who were not brought to health care services, especially children that were given traditional treatments at home.

Our survey sample has similar demographic characteristics to the rural portion of past surveys, using the same sampling scheme, the same survey organization, and the same questions. However, we found a higher than expected prevalence for all three conditions. In the DHS [14] conducted in 2008 the two week prevalence rate of diarrhoea among the rural sample (similar to our sample) was $13.7 \%$, for presumed pneumonia $7.4 \%$ and for fever $24.4 \%$ much lower than in our survey. Similarly, in the rural sample of the SLDHBS conducted in 2009 [15] the rates for diarrhoea were $10.5 \%$, presumed pneumonia $5.2 \%$ and fever $21.2 \%$ again much lower than what we found. Our finding of higher levels of child morbidity than in previous surveys may be because we conducted the survey in the wet season while the other surveys were conducted in the dry season. During the wet season, illnesses, especially malaria, are usually higher. Additionally with the FHCI, respondents may be overreporting illnesses in anticipation of receiving free services. The location of the questions within the survey and the skip patterns may have differed slightly from DHS and SLDHS which were much larger questionnaires, and we used a PDA, we do not know if these factors resulted in higher rates of reporting symptoms.

With regards to health care seeking, both quantitative survey and qualitative findings found higher levels than what was reported in surveys prior to FHCI. Our finding of higher healthcare seeking behaviours after FHCI is supported by data from the 2010 MICS survey conducted during the dry season 5 months after FHCI which found $74.3 \%$ of rural children with presumed pneumonia being brought to a health care provider [16]. These findings suggest that the FHCI resulted in an increased uptake of government health services. Increase in healthcare seeking after removal of user fees has been documented extensively in Africa [17-25]. These increases primarily benefit the poor $[19,26]$.

Even though we found high healthcare seeking, a large proportion of children did not receive the recommended treatment they should have based on symptom reporting. Although receiving treatment from a peddler or someone other than government health personnel was more common among those not receiving recommended treatments, nurses, health aides, community health officers and doctors still provided the majority of not recommended treatments. In the qualitative study we found that the use of these alternative providers was in part due to unavailability of medicines at facilities and that families retained a critical perspective of providers, valuing those that provided effective treatment. Poor quality treatment and/or stock outs can undermine the potential impact of providing free health care. In Sierra Leone despite FHIC in some instances, drugs and other essential medical supplies was simply not available (Kabano A., UNICEF Sierra Leone, direct communication 2012) and there are claims that sometimes women were still charged for services [27]. In other countries abolition of user fees without proper planning did result in a decrease in overall quality of services, revenues and increases in difficulties meeting recurrent expenses such as purchasing medications [22,27-30].

Finally among the small proportion of ill children for whom families did not seek health care outside the home, those who used traditional treatments at home, were the most likely not to seek care. Qualitative data detailed households seeking traditional treatment due to preference and due to lack of alternatives. Delays in 
seeking treatment have been found to be associated with use of home treatments or self-medication in other countries in sub-Saharan Africa $[25,31,32]$. In addition, we found that children with diarrhoea who had multiple symptoms were more likely to be brought to a health care facility. Other studies in sub-Saharan Africa have also found that those with multiple symptoms were more likely to be brought to care [33,34].

With regards to social determinants, several studies have found an association between health care seeking and socioeconomic status as well as an association with mother's level of education [33-36] but we did not find such an association except among children with presumed pneumonia where we found an opposite association than expected, children of lowest wealth quintile were actually more likely to seek healthcare. Perhaps the FHIC removed financial barriers to care, but we also must consider the fact that the population in our districts were uniformly poor so differences by wealth quintile may not be very large. Finally, in the household survey we did not find an association with distance from health facilities as has been found in other studies [31,33,35]. However, this lack of association may be because we only calculated a straight line distance, and did not take into account geographic obstacles (e.g. lack of roads, rivers, mountains) that could impact healthcare seeking. In the qualitative findings, respondents did report geographic obstacles as reasons for not seeking health care, particularly for those respondents living in more remote villages or that lived across roads and rivers that became impassable during the rainy seasons, living on islands, etc.

There are several further limitations to our research. Our survey was designed to inform and evaluate the CCM program that would be put in place and not the FHCI. It therefore did not include a pre and post FHCI survey design; however, other surveys conducted before and after the FHCI support our findings. We relied on self-reported symptoms and types of treatments; actual diagnosis of conditions may differ from reported symptoms and despite the use of pictures caretakers may not always accurately report what they received. We assumed inappropriate treatment based on symptoms but the actual physical exam may have revealed signs resulting in another diagnosis. As the qualitative research explored all three child morbidities of interest, respondent fatigue may have affected the quality of some responses.

\section{Conclusions}

Our findings suggest increased healthcare seeking in the context of FHCI, but also point to the urgent need to improve facility level care to ensure proper diagnosis and treatment so as to avoid undermining the impact of providing free health care in all 4 districts surveyed. Our qualitative findings in particular highlight numerous barriers to care that still need to be addressed for child survival. For the 2 districts that will implement CCM the program should be designed to ensure proper diagnosis and treatment and target services to persons who still do not access care despite the FHIC.

\section{Abbreviations}

ACT: Artemisinin-based combination therapies; CCM: Community case management; CHV: Community health volunteer; DHS: Demographic health survey; FHIC: Free health care initiative; MICS: Multiple indicator survey; ORS: Oral rehydration solution; PDA: Personal digital assistant; SLDHBS: Sierra Leone district health services baseline survey.

\section{Competing interests}

The authors declare they have no competing interests.

\section{Authors' contributions}

All authors contributed to the conception of the study. TD AG SM SR designed the study and analysed the data. PB was responsible for overseeing the data collection. All authors reviewed the data analysis and then provided interpretation of the findings. TD and AG drafted the manuscript and all other authors provided revisions. All authors have given final approval of the manuscript.

\section{Acknowledgements}

The authors thank all the family respondents, village leaders and local officials for their time and assistance in supporting this research. We especially would like to thank Adam Wolkon from CDC for programming the PDAs and providing training in their use. We also thank Mark Laponte, Ahmet Afsar and Lianne Kuppens for ground coordination and Fatu Yumkella and her investigators for the qualitative data collection. In addition, we appreciated feedback from implementing partners including Ministry of Health and Social Welfare, International Rescue Committee, Save the Children, and CARE, as well as technical advice provided by Maria Nunez, Gary Shapiro (Statistics Without Borders) and Bobbie Person. This work was undertaken with funds from the Canadian International Development Association and is supported by the United Nations Children Emergency Fund (UNICEF).

\section{Author details}

${ }^{1}$ Knowledge Management and Implementation Research Unit, Health Section, Programme Division, United Nations Children's Fund (UNICEF), New York NY, USA. ²Department of International Health, Bloomberg School of Public Health, John Hopkins University, Baltimore, MD, USA. ${ }^{3}$ Statisticians without Borders, American Statistical Society, Department of Quantitative Health Sciences, University of Massachusetts Medical School, Worcester MA USA. ${ }^{4}$ Center for Health Quality, Outcomes, and Economics Research, Bedford VA Medical Center, Bedford, MA, USA. ${ }^{5}$ Statistics Sierra Leone, Freetown, Sierra Leone. ${ }^{6}$ United Nations Children Fund (UNICEF), Freetown, Sierra Leone.

Received: 22 June 2012 Accepted: 5 February 2013

Published: 20 February 2013

\section{References}

1. United Nations Inter-agency Group for Child Mortality Estimation: Levels and trends in child mortality. New York, New York: United Nations Children's Fund; 2011.

2. World Health Organization and UNICEF: Countdown to 2015 (200-2010) Decade Report (2000-2010): Taking stock of maternal, newborn and child survival. New York: United Nation Children's Fund; 2010.

3. Donnelly J: How did Sierra Leone provide free health care? Lancet 2011, 377:1393-1396.

4. Haine A, Sanders D, Lehmann U, et al: Achieving child survival goals: potential contribution of community health workers. Lancet 2007, 369:2121-31. 
5. Yeboah-Antwi K, Pilingana $P$, Macleod WB, et al: Community case management of fever Due to malaria and pneumonia in children under five in Zambia: a cluster randomized controlled trial. PLoS Med 2010, 7(9):e1000340.

6. Dawson $P$, Pradhan $Y$, Houston $R$, et al: From research to national expansion: 20 years of experience of community-based management of childhood pneumonia in Nepal. Bull World Health Organ 2008, 86:339-43.

7. Kalyango JN, Lindstrand A, Rutebemberwa E, et al: Integrated community case management of fever increases utilization of community medicine distributors and rational use of drugs in under-fives in Uganda. Am J Trop Med Hyg 2012, 87(5 Suppl):36-45.

8. VandenEng JL, Wolkon A, Terlouw DJ, et al: Use of handheld computers with global positioning systems for probability sampling and data entry in household surveys. AmJTrop Med Hyg 2007, 7:393-9.

9. Institute InC SAS: Base $S A S^{\circledR}$ 9.1.3 procedures guide, volumes 1, 2, 3, and 4 . Secondth edition. Cary, NC: SAS Institute Inc; 2006.

10. Shea Oscar Rutstein SO, Johnson K: The DHS wealth index. DHS Comparative Reports No. 6. Calverton, Maryland: ORC Macro; 2004.

11. Pelto PJ, Pelto GH: Studying knowledge, culture, and behavior in applied medical anthropology. Med Anthropol Q 1997, 11(2):147-163.

12. Nichter M: Use of social science research to improve epidemiologic studies of and interventions for diarrhea and dysentery. Rev Infect Dis 1991, 13(Suppl 4):S265-271.

13. ATLAS: User's Manual for ATLAS.ti 5.0. Copyright (c) 2003-2004 by Thomas Muhr. 2nd edition. Berlin: ATLAS.ti Scientific Software Development; 2004.

14. Statistics Sierra Leone (SSL) and ICF Macro. 2009. Sierra Leone Demographic and Health Survey: Calverton, Maryland. Statistics Sierra Leone (SSL) and ICF Macro: USA; 2008

15. Statistics Sierra Leone and Ministry of Health and Sanitation: Sierra Leone district health services baseline survey 2009. Freetown, Sierra Leone: Statistics Sierra Leone and Ministry of Health and Sanitation; 2010.

16. Statistics Sierra Leone and Ministry of Health and Sanitation: Multiple indicator survey 2010. Freetown, Sierra Leone: Statistics Sierra Leone and Ministry of Health and Sanitation; 2012.

17. Burnham GM, Pariyo G, Galiwango E, Wabwire-Mangen F: Discontinuation of cost sharing in Uganda. Bull World Health Organ 2004, 82:187-195.

18. James $C D$, Hanson $K$, Cake $B$, et al: To retain or remove user fees? reflections on the current debate in low- and middle-income countries. Appl Health Econ Health Policy 2006, 5:137-53.

19. Fafchamps M, Minten B: Public service provision. User Fees and Political Turmoil Journal of African Economies 2007, 16:485-518.

20. Riddle $\mathrm{V}$, Morestin F: A scoping review of the literature on the abolition of user fees in health care services in Africa. Health Policy Plan 2011, 26:1-11.

21. Lagarde M, Palmer N: The impact of user fees on access to health services in low- and middle-income countries. Cochrane Database Syst Rev 2011, 13:CD009094. Published Online: 13 APR 2011.

22. Ponsar F, Van Herp M, Zachariah R, Gerard S, Philips M, Jouquet G: Abolishing user fees for children and pregnant women trebled uptake of malaria-related interventions in Kangaba. Mali Health Policy Plan 2011, 26(suppl 2):ii72-ii83.

23. Witter $S$, Khadka S, Nath $H$, Suresh $T$ : The national free delivery policy in Nepal: early evidence of its effects on health facilities. Health Policy Plan 2011, 26(suppl 2):ii84-ii91.

24. Steinhardt LC, Aman I, Pakzad I, Kumar B, Singh LP, Peters DH: Removing user fees for basic health services: a pilot study and national roll-out in Afghanistan. Health Policy Plan 2011, 26(suppl 2):ii92-ii103.

25. Page AL, Hustache S, Luquero FJ, Djibo A, Manzo ML, Grais RF: Health care seeking behavior for diarrhea in children under 5 in rural Niger: results of a cross-sectional survey. BMC Publ Health 2011, 11:389.

26. Witter S, Arhinfu DK, Kusi A, Zakariah-Akoto S: The experience of Ghana in implementing a user fee exemption policy to provide free delivery care. Reprod Health Matters 2007, 15:61-71.

27. Moszynski P: Sierra Leone's maternal health reforms fail to deliver free treatment, says amnesty international. BMJ 2011, 343:d5645.

28. Meissen B, Her Cot D, Noirhomme M, Ridde V, Tibouti A, Tashobya CK, Gilson L: Removing user fees in the health sector: a review of policy processes in six sub-Saharan African countries. Health Policy Plan 2011 26(suppl 2):ii16-ii29.

29. Orem JN, Mugisha F, Kirunga C, Macq J, Criel B: Abolition of user fees: the Uganda paradox. Health Policy Plan 2011, 26(suppl 2):ii41-ii51.
30. Nimpagaritse M, Bertone MP: The sudden removal of user fees: the perspective of a frontline manager in Burund. Health Policy Plan 2011, 26(suppl 2):ii63-ii71.

31. Källander K, Kadobera D, William TN: Social autopsy: INDEPTH Network experiences of utility, process, practices, and challenges in investigating causes and contributors to mortality. Population Health Metrics 2011, 9:44-56.

32. Colvin CJ, Smith H, Swartz A, Ahs JW, De Heer J, Opiyo N, Kim J, Marraccini T, George A: Household recognition and response to child diarrhoea, pneumonia and malaria in Sub-Saharan Africa: a systematic qualitative review, submitted to Plos.

33. Burton DC, Flannery B, Onyango B: Healthcare-seeking behavior for common infectious disease-related illnesses in rural Kenya: a community-based house-to-house survey. J Health Popul Nutr 2011, 29:61-70.

34. Ndugwa RP, Zulu EM: Child morbidity and care-seeking in Nairobi slum settlements: the role of environmental and socio-economic factors. J Child Health Care 2008, 12:314-28.

35. Rutebemberwa E, Kallander K, Tomson G, Peterson S, Pariyo G: Determinants of delay in care-seeking for febrile children in eastern Uganda. Trop Med Int Health 2009, 14:472-479.

36. Schellenberg JA, Victoria CG, Mushi A: Inequities among the very poor: health care for children in rural southern Tanzania. Lancet 2003, 15:561-566.

doi:10.1186/1471-2458-13-157

Cite this article as: Diaz et al:: Healthcare seeking for diarrhoea, malaria and pneumonia among children in four poor rural districts in Sierra Leone in the context of free health care: results of a cross-sectional survey. BMC Public Health 2013 13:157.

\section{Submit your next manuscript to BioMed Central and take full advantage of:}

- Convenient online submission

- Thorough peer review

- No space constraints or color figure charges

- Immediate publication on acceptance

- Inclusion in PubMed, CAS, Scopus and Google Scholar

- Research which is freely available for redistribution 